\title{
Wavelength conversion of a 40-Gb/s NRZ signal across the entire C-band by an asymmetric Sagnac loop
}

\section{Citation for published version (APA):}

Jansen, S. L., Chayet, H., Granot, E., Ben Ezra, S., Borne, van den, D., Krummrich, P. M., Chen, D., Khoe, G. D., \& Waardt, de, H. (2005). Wavelength conversion of a 40-Gb/s NRZ signal across the entire C-band by an asymmetric Sagnac loop. IEEE Photonics Technology Letters, 17(10), 2137-2138. https://doi.org/10.1109/LPT.2005.854427

DOI:

10.1109/LPT.2005.854427

Document status and date:

Published: 01/01/2005

\section{Document Version:}

Publisher's PDF, also known as Version of Record (includes final page, issue and volume numbers)

\section{Please check the document version of this publication:}

- A submitted manuscript is the version of the article upon submission and before peer-review. There can be important differences between the submitted version and the official published version of record. People interested in the research are advised to contact the author for the final version of the publication, or visit the $\mathrm{DOI}$ to the publisher's website.

- The final author version and the galley proof are versions of the publication after peer review.

- The final published version features the final layout of the paper including the volume, issue and page numbers.

Link to publication

\section{General rights}

Copyright and moral rights for the publications made accessible in the public portal are retained by the authors and/or other copyright owners and it is a condition of accessing publications that users recognise and abide by the legal requirements associated with these rights.

- Users may download and print one copy of any publication from the public portal for the purpose of private study or research.

- You may not further distribute the material or use it for any profit-making activity or commercial gain

- You may freely distribute the URL identifying the publication in the public portal.

If the publication is distributed under the terms of Article 25fa of the Dutch Copyright Act, indicated by the "Taverne" license above, please follow below link for the End User Agreement:

www.tue.nl/taverne

Take down policy

If you believe that this document breaches copyright please contact us at:

openaccess@tue.nl

providing details and we will investigate your claim. 


\title{
Wavelength Conversion of a $40-\mathrm{Gb} / \mathrm{s}$ NRZ Signal Across the Entire $C$-Band by an Asymmetric Sagnac Loop
}

\author{
S. L. Jansen, Student Member, IEEE, H. Chayet, E. Granot, S. Ben Ezra, D. den van Borne, Student Member, IEEE, \\ P. M. Krummrich, Member, IEEE, D. Chen, G. D. Khoe, Fellow, IEEE, and H. De Waardt
}

\begin{abstract}
A compact integrated all-optical wavelength converter based on an asymmetric Sagnac loop is demonstrated. We show that a 40-Gb/s nonreturn-to-zero data signal can be converted over the entire $C$-band employing an asymmetric Sagnac loop. Compared to the back-to-back configuration, a receiver sensitivity power penalty of less then $2.1 \mathrm{~dB}$ is measured for both up- and down-conversion.
\end{abstract}

Index Terms-All-optical devices, fiber-optics communications, semiconductor optical amplifiers (SOAs).

\section{INTRODUCTION}

A LL-OPTICAL wavelength conversion is a key feature for reducing wavelength blocking in wavelength-division-multiplexing all-optical networks. It enhances routing options and enables wavelength reuse [1]. Extensive research has been devoted to various schemes of all-optical wavelength converters; Mach-Zehnder interferometers [2], [3], nonlinear optical loop mirrors [4], periodically poled lithium-niobate (PPLN) [5], and Sagnac loops [6]-[8]. For the nonreturn-to-zero (NRZ) modulation format, only the PPLN has achieved successful conversion at $40 \mathrm{~Gb} / \mathrm{s}$ [5]. All other devices capable of operating with the NRZ format were limited to a data rate of $10 \mathrm{~Gb} / \mathrm{s}$. The asymmetric Sagnac loop wavelength converter with a semiconductor optical amplifier (SOA) is one of the schemes that received significant interest in the last few years [6]-[8]. Originally, the Sagnac loop was proposed for return-to-zero (RZ) modulation [9]. However, recently, the scheme was extended to $10-\mathrm{Gb} / \mathrm{s}$ NRZ operation [6].

In this letter we are, to the best of our knowledge, the first to present an asymmetric Sagnac-loop-based wavelength converter for $42.7-\mathrm{Gb} / \mathrm{s} \mathrm{NRZ} \mathrm{signals.} \mathrm{We} \mathrm{show} \mathrm{that} \mathrm{the} \mathrm{Sagnac} \mathrm{loop}$ is capable of converting wavelengths over the entire $C$-band

Manuscript received April 4, 2005; revised June 22, 2005. This work was supported by the University of Technology Eindhoven, The Netherlands, by Siemens AG, Munich, Germany, by MCI, Richardson, TX, and by KaiLight, Rehovot, Israel.

S. L. Jansen, D. van den Borne, G. D. Khoe, and H. de Waardt are with the COBRA Institute, Eindhoven University of Technology, Eindhoven 5612, The Netherlands (e-mail: s.l.jansen@tue.nl; dirk@vandenborne.com; h.d.waardt@tue.nl, g.d.khoe@tue.nl).

H. Chayet, E. Granot, and S. B. Ezra are with KaiLight, Rehovot 76124, Israel (e-mail: haim.c@kailight.com; erel.g@kailight.com; shalva.b@kailight.com).

P. M. Krummrich is with the Siemens AG, COM, Carrier Products, Munich D-81359, Germany (e-mail: peter.krummrich@ siemens.com).

D. Chen is with MCI, Richardson, TX 75080 USA (e-mail: david.chen@mci.com).

Digital Object Identifier 10.1109/LPT.2005.854427

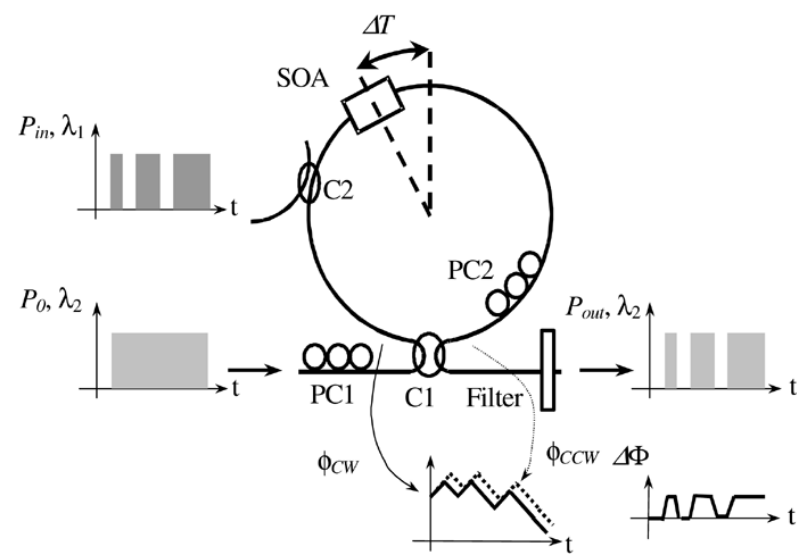

Fig. 1. Sagnac schematic; $P_{\text {in }}$ is the input signal at the original wavelength $\lambda_{1}, P_{0}$ is the continuous wave signal at wavelength $\lambda_{2}$. PC1 and PC2 are polarization controllers, and $\mathrm{C} 1$ and $\mathrm{C} 2$ are optical couplers; $\varphi_{\mathrm{CLW}}$ and $\varphi_{\mathrm{CCLW}}$ are the phases of the CLW and CCLW propagating signal components, respectively. The spectral bandpass filter is used to block the incoming signal wavelength $\lambda_{1}$.

with a sensitivity penalty of less than $2.1 \mathrm{~dB}$ compared with back-to-back operation.

\section{PRINCIPLE OF OPERATION}

The Sagnac loop is shown schematically in Fig. 1. The Sagnac loop used in this experiment has an asymmetric configuration; the SOA is moved $\Delta T$ from the center of the loop, where $\Delta T$ is a propagation time interval. A $50: 50$ coupler (C1) splits the incident signal $P_{0}$ into clockwise (CLW) and counterclockwise (CCLW) propagating components. A data signal is input into the device through the $20 \%$ port of a $20: 80$ coupler (C2). Both the CLW and the CCLW components experience cross-gain modulation (XGM) and cross-phase modulation (XPM) inside the SOA. Signal $P_{0}$ and the data signal will have, in general, different polarizations. Since the effective refractive index of the transverse-electric and transverse-magnetic modes change differently, they will also experience cross-polarization modulation [10].

As mentioned in the introduction, the Sagnac loop was originally introduced for RZ operation. In RZ operation [9], a pulse rather than a continuous wave is introduced into the Sagnac loop through coupler C1 (Fig. 1). Due to the high peak power of this pulse, the SOA is saturated. The CLW and the CCLW part pass the SOA before and after the data pulse and, therefore, experience a different phase shift. Interference is altered by the nonlinearity of the SOA. For NRZ operation, the original data signal 


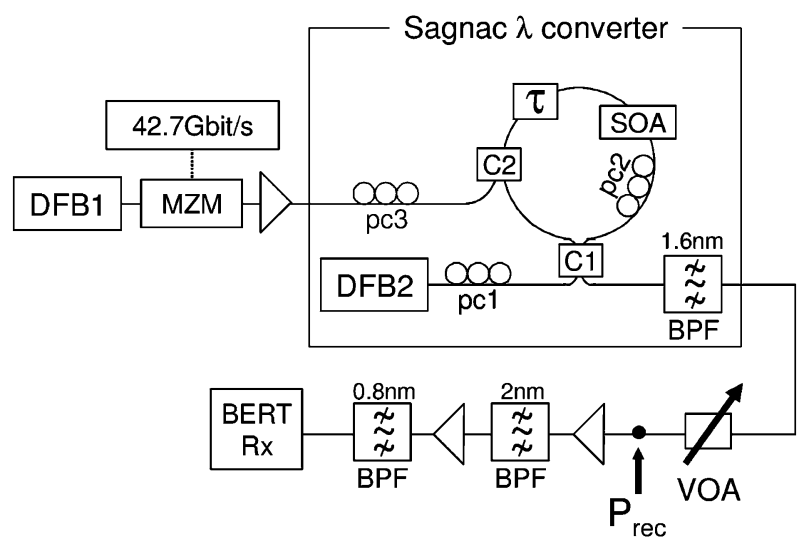

Fig. 2. Experimental setup.

is converted to a continuous wave instead of a pulsed signal. As a result, a faster SOA is required since the pulse shaping finds place inside the Sagnac loop. The XPM-induced phases of CCLW and CLW are shifted in time, as shown in the inset of Fig. 1. Here in addition to the time shift, a constant difference between the $\varphi_{\mathrm{CLW}}$ and the $\varphi_{\mathrm{CCLW}}$ is introduced by the birefringence of the loop. Thus, when the SOA is offset from the center the interference at the output coupler is determined both by XPM and cross-polarization modulation. By adjusting the PC2 and the delay line $(\Delta T)$, it is possible to improve the extinction ration (ER) of the output signal. A more detailed description of this principle and the general operation of the Sagnac loop in combination with the NRZ data format can be found in [7].

\section{EXPERIMENTAL SETUP}

In Fig. 2, the experimental setup is depicted that was used to measure the performance of the wavelength converter. A distributed feedback (DFB) laser (DFB1) generated a continuous-wave signal at $1552.1 \mathrm{~nm}$. This continuous-wave signal was NRZ modulated with a $2^{31}-1$ pseudorandom binary sequence at $42.7 \mathrm{~Gb} / \mathrm{s}$ by a Mach-Zehnder modulator. Before the wavelength converter, an erbium-doped fiber amplifier (EDFA) boosted the signal to a power level of $10 \mathrm{dBm}$. After the EDFA, the signal was inserted in the Sagnac loop. The 700- $\mu \mathrm{m}$-long SOA used in the Sagnac loop had a response time of approximately 65-75 ps and was operated at an injection current of $220 \mathrm{~mA}$. The gain peak was present at $\sim 1540 \mathrm{~nm}$ and the saturation power was $9.0 \mathrm{dBm}$. The saturated and nonsaturated gain was 3 and $27 \mathrm{~dB}$, respectively. A continuous-wave signal at a different wavelength was created by a second DFB laser (DFB2). This signal was inserted into the Sagnac with a power of $9 \mathrm{dBm}$.

The performance of the wavelength converter was optimized by adjusting the polarization of the inserted continuous-wave signal (PC1) and the polarization within the Sagnac loop (PC2). Another parameter to be set is the delay of the loop $(\Delta T)$. The SOA used in this setup had a polarization dependence of about $1 \mathrm{~dB}$, hence, a third polarization controller (PC3) was used to control the polarization of the incoming data channel. With a polarization-independent SOA, this polarization controller will no longer be required. In order to measure the receiver sensitivity of the system, a variable optical attenuator was inserted before the receiver. In the receiver, the signal was amplified by

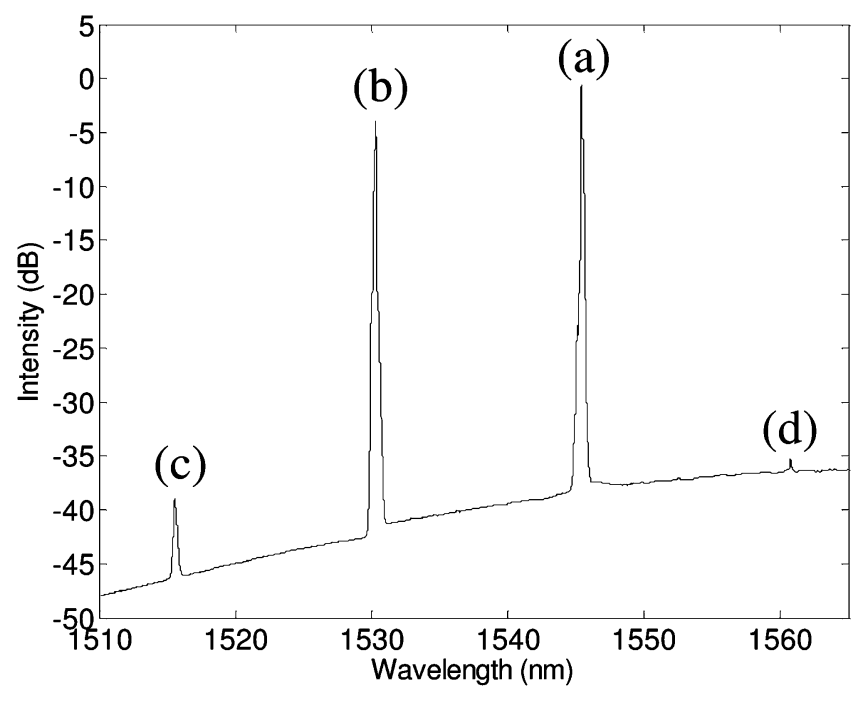

Fig. 3. Optical spectrum after conversion, before the bandpass filter (resolution bandwidth of $0.1 \mathrm{~nm}$ ).

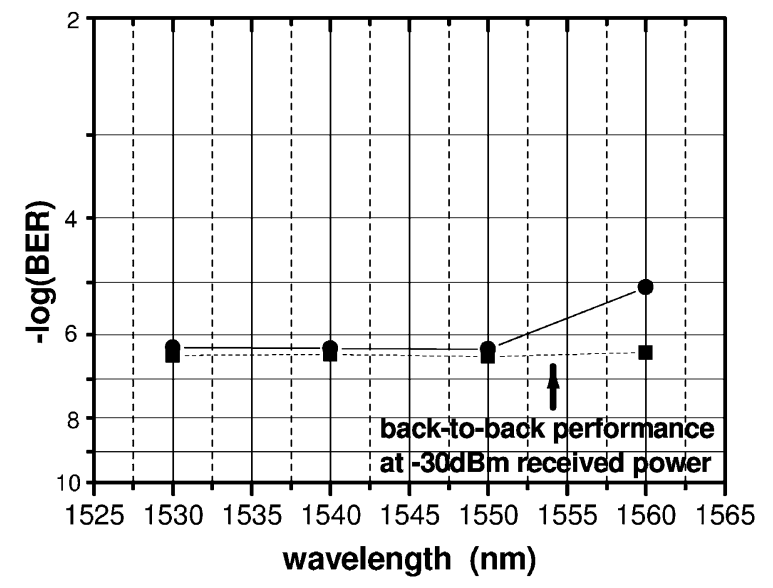

Fig. 4. BER as a function of the converted wavelength at $-30-\mathrm{dBm}$ optical power at the receiver. The original data signal was present at $1545 \mathrm{~nm}$.

an EDFA and band-limited by a 0.8-nm (full-width at half-maximum) bandpass filter. Finally, the signal was received by a bit-error-rate (BER) tester.

\section{RESULTS}

The optical spectrum after conversion, before the 1.6-nm bandpass filter, is depicted in Fig. 3. The original data signal [Fig. 3(a)] can be seen at $1545 \mathrm{~nm}$. The continuous-wave signal [Fig. 3(b)] can be seen at $1530 \mathrm{~nm}$. At 1515 [Fig. 3(c)] and $1560 \mathrm{~nm}$ [Fig. 3(d)] small four-wave mixing (FWM) products are present. The FWM products are blocked by the 1.6-nm bandpass filter after the wavelength converter and, hence, do not affect the performance of the conversion.

In this Sagnac structure, the incoming signal with wavelength $\lambda_{1}$ can be converted to any wavelength $\lambda_{2}$ within the $C$-band as long as the original and converted channels do not overlap. Fig. 4 shows the back-to-back BER performance of the $42.7-\mathrm{Gb} / \mathrm{s}$ NRZ signal for wavelength conversion from $1545 \mathrm{~nm}$ to wavelengths across the entire $C$-band.

The received optical power in these measurements was $-30 \mathrm{dBm}$. The back-to-back performance without wave- 

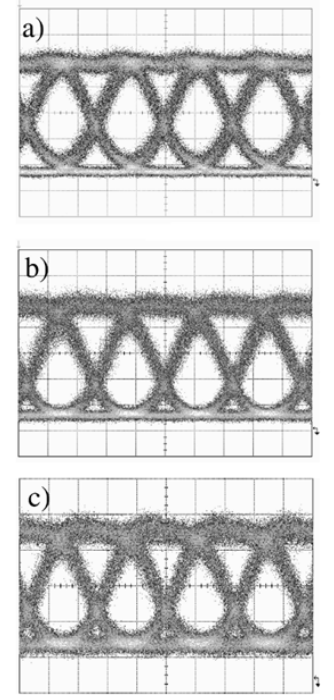

Fig. 5. Eye diagrams of the 40-Gb/s data; (a) without wavelength conversion, (b) with conversion from 1545 to 1540 , (c) with conversion from 1545 to 1560 .

length conversion (the dashed line) was $\sim 3.5 * 10^{-7}$. With the Sagnac-based wavelength converter, the BER increased to $4.5 * 10^{-7}$ and $8.3 * 10^{-6}$ for the best and the worst conversion, respectively. Wavelength conversion from 1530 to $1560 \mathrm{~nm}$ and from 1560 to $1530 \mathrm{~nm}$ was measured as well. The BER from 1560 to $1530 \mathrm{~nm}$ was $4.2 * 10^{-7}$, the BER from 1530 to $1560 \mathrm{~nm}$ was $5 * 10^{-6}$.

From Fig. 4, we conclude that the performance of up-conversion, i.e., conversion from lower to higher wavelengths, is worse than the performance of down-conversion. We believe that the performance difference between up-conversion and down-conversion is due to a decreased XGM efficiency for up-conversion. As a result, the extinction ratio of the output signal is lower for up-conversion. This wavelength dependence of the XGM is attributed to the spectral dependence of the differential gain of the SOA, which decreases monotonically with increasing wavelength [11].

In Fig. 5, the eye diagrams of the back-to-back operation, and for the best (from 1545 to $1540 \mathrm{~nm}$ ) and the worst (from 1545 to $1560 \mathrm{~nm}$ ) conversion settings are depicted. It can be seen that the eye diagram of the worst conversion is noisier and has a lower extinction ratio than the eye diagram of the best conversion. From both the best wavelength and worst wavelength conversion eye diagrams, it can be concluded that the crossing point between the bits is slightly lowered. However, the "one" level is constant in the eye diagram. A faster SOA could help maintain the level of the crossing point in the middle.

The optical power at the receiver as a function of the BER with and without wavelength conversion is shown in Fig. 6. In this plot, the best (from 1545 to $1540 \mathrm{~nm}$ ) and the worst (from 1545 to $1560 \mathrm{~nm}$ ) conversion settings are depicted. For the best wavelength conversion, the receiver power penalty compared to back-to-back is smaller than $0.4 \mathrm{~dB}$. The worst wavelength conversion setting results in a receiver power penalty of less than $2.1 \mathrm{~dB}$. Error-free conversion (BER of lower than $1 * 10^{-12}$ ) was measured for all wavelength configurations.

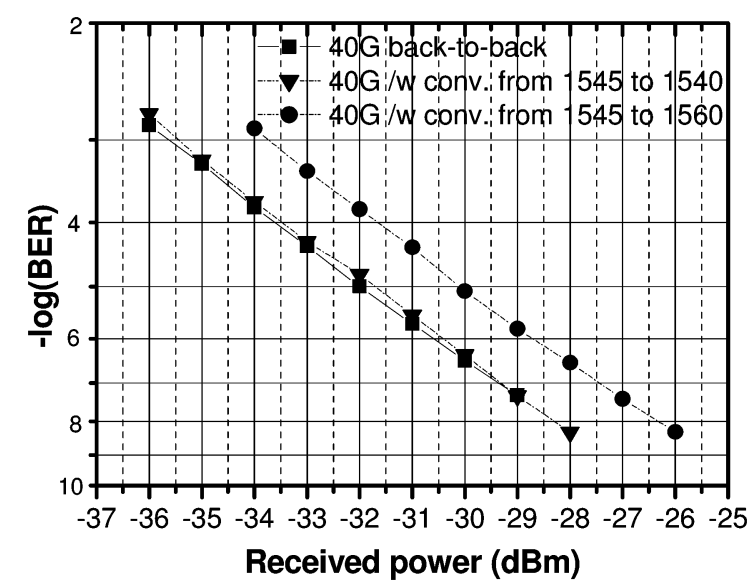

Fig. 6. BER as a function of the optical power at the receiver for the back-to-back 42.7-Gb/s system, with and without optical wavelength conversion.

\section{CONCLUSION}

We have shown for the first time that a Sagnac loop can be employed for wavelength conversion of a 42.7-Gb/s NRZ signal across the entire $C$-band. Compared to back-to-back operation, the receiver sensitivity power penalty was less then $2.1 \mathrm{~dB}$ for all measured wavelength conversion configurations.

\section{REFERENCES}

[1] R. Ramaswami and K. N. Sivarajan, Optical Networks, a Practical Perspective. San Mateo, CA: Morgan Kaufmann, 1998.

[2] J. Y. Emery et al., "Optimized 2-R all-optical regenerator with low polarization sensitivity penalty $(<1 \mathrm{~dB})$ for optical network applications," in Tech. Dig. OFC, Anaheim, CA, 2001, Paper Mb4-1.

[3] W. Idler et al., " $10 \mathrm{~Gb} / \mathrm{s}$ wavelength conversion with integrated multiquantum-well-based 3-port Mach-Zehnder interferometer," IEEE Photon. Technol. Lett., vol. 8, no. 9, pp. 1163-1163, Sep. 1996.

[4] F. Seguineau et al., "Experimental demonstration of simple NOLMbased $2 \mathrm{R}$ regenerator for $42.66 \mathrm{Gbit} / \mathrm{s}$ WDM long-haul transmissions," in $O F C$, Los Angeles, CA, 2004, Paper WN4.

[5] S. L. Jansen et al., " $16 \times 40$ over $800 \mathrm{~km}$ of SSMF using midlink spectral inversion," IEEE Photon. Technol. Lett., vol. 16, no. 7, pp. 1763-1765, Jul. 2004.

[6] L. Xu, V. Baby, I. Glesk, and P. R. Prucnal, "Novel all-optical NRZ wavelength conversion employing SOA-based Sagnac interferometer," in CLEO/IQEC and PhAST 2004, San Francisco, CA, 2004, Paper CFG1.

[7] L. Xu, I. Glesk, V. Baby, and P. R. Prucnal, "All-optical wavelength conversion using SOA at nearly symmetric position in a fiber-based Sagnac interferometer loop," IEEE Photon Technol. Lett., vol. 16, no. 2, pp. 539-541, Feb. 2004.

[8] H. Chayet, S. B. Ezra, N. Narkiss, and S. Zadok, "Compensation of chromatic dispersion by chirp control in all-optical regenerator based on asymmetric Sagnac loop," in OFC, Anaheim, CA, 2005, Paper OFK6.

[9] K. L. Deng, I. Glek, K. I. Kang, and P. R. Prucnal, "Unbalanced TOAD for optical data and clock separation in self-clocked transparent OTDM networks," IEEE Photon Technol. Lett., vol. 9, no. 6, pp. 830-832, Jun. 1997.

[10] H. Soto, D. Erasme, and G. Guekos, "Cross-polarization modulation in semiconductor optical amplifiers," IEEE Photon. Technol. Lett., vol. 11, no. 8, pp. 970-972, Aug. 1999.

[11] K. Obermann, S. Kindt, D. Breuer, and K. Petermann, "Performance analysis of wavelength converters based-gain modulation in semiconductor-optical amplifier," J. Lightw. Technol., vol. 16, no. 1, pp. 78-85, Jan. 1998. 